\title{
Disclosing Parental Human Immunodeficiency Virus (HIV) Status to Children in Ghana: Reasons for and against Disclosure and Effects of Decision
}

\author{
Raphael Avornyo ${ }^{1}$, John Amoah ${ }^{2}$ \\ ${ }^{1}$ Department of Sociology and Anthropology, Faculty of Social Sciences, University of Cape Coast, Cape Coast, \\ Ghana \\ ${ }^{2}$ Institute for Development Studies, Faculty of Social Sciences, University of Cape Coast, Cape Coast, Ghana \\ Email: ${ }^{*}$ raphael.avornyo@ucc.edu.gh, ${ }^{*}$ raphaelavornyo@hotmail.com, johnzox21@yahoo.com
}

Received 1 August 2014; revised 20 August 2014; accepted 26 August 2014

Copyright (C) 2014 by authors and Scientific Research Publishing Inc.

This work is licensed under the Creative Commons Attribution International License (CC BY). http://creativecommons.org/licenses/by/4.0/

(c) (i) Open Access

\section{Abstract}

There is limited data regarding HIV disclosure in Ghana. This study sought to examine parental disclosure of HIV status to children, ascertain reasons for disclosure and nondisclosure and also the effects of parents' decision. 26 parents living with HIV and 21 children were selected in Accra and Cape Coast purposively and conveniently and interviewed. Out of a total of 26 parents living with HIV, the majority numbering 18, made up of two males and 16 females had not disclosed their status. Reasons for nondisclosure included: fear of stigmatization and discrimination; children being too young; not wanting the children to get worried; and children thinking their parents would die. The majority of those, who had done the disclosure, were young. One effect was that most children became sad, after the status of their parents had been disclosed to them. They, however, readjusted and provided support to their parents. Another effect was that the children became knowledgeable or more knowledgeable about HIV and AIDS. In a country, where HIV is seen as a shameful disease, Persons Living with HIV (PLHIV) experience massive stigmatization and discrimination. Intensification of the fight against stigmatization and discrimination and equipping of PLHIV with skills necessary for disclosure are critical.

\section{Keywords}

Human Immunodeficiency Virus (HIV), Disclosure, Parents, Children, Ghana

\footnotetext{
${ }^{*}$ Corresponding author.
}

How to cite this paper: Avornyo, R., \& Amoah, J. (2014). Disclosing Parental Human Immunodeficiency Virus (HIV) Status to Children in Ghana: Reasons for and against Disclosure and Effects of Decision. Advances in Applied Sociology, 4, $205-211$. 


\section{Background}

Ever since HIV reared its ugly face in Ghana in 1986, the country has been working hard to mitigate the impact of the disease. It has set up two national bodies, namely the National AIDS Control Program (NACP) and the Ghana AIDS Commission (GAC) to spearhead an effective response to the epidemic. With support from national and international partners, these two bodies have adopted strategies to reduce the impact of the disease (Amoa, 2005). One of such strategies is the "Heart-to-Heart" Campaign initiated by the GAC in partnership with the Network of Associations of Persons Living with HIV (NAP + Ghana). The ultimate aim of this project is to help reduce stigmatization of and discrimination against Persons Living with HIV (PLHIV). Despite the efforts being made to reduce stigmatization and discrimination through the education of the public and the internal disclosure of the HIV status of the members of the "Heart-to-Heart" Campaigners, stigmatization and discrimination are still rife in the country.

Studies conducted in different parts of the world including sub-Saharan Africa indicate that a lot of benefits are derived through disclosure. Mkwanazi, Rochat, Imrie, \& Bland (2012), in their review of literature on disclosure, present the benefits that parents, who disclose their status to their children, derive as well as the benefits that children, to whom the status of their parents are disclosed, derive. These benefits include psychological benefits, social benefits and physical health benefits (Mkwanazi, Rochat, Imrie, \& Bland, 2012).

However, in a country like Ghana, where stigmatization of and discrimination against PLHIV are high, parents living with HIV are less likely to disclose their status. According to Bachanas, Kullgren, Schwartz, Lanier, McDaniel, Smith, \& Nesheim (2001), parents' failure to disclose their status to their children may lead to psychological disturbances in children and families. With the introduction of anti-retroviral therapy (ART) in Ghana, there are more and more families in which parents living with HIV have children. Most of these children are not given the needed help, so that they can be psychologically balanced. They may be suspecting that their parents may be having health challenges, but because they are not told the truth they may be disturbed. According to Qiao, Li, \& Stanton (2013), the largest population of HIV-infected parents lives in Africa. However, very little research has examined HIV disclosure in this region. Ghana is one such country in the region. This study, therefore, seeks to examine the reasons for disclosure and nondisclosure and what effects these have on individuals, families and the nation at large.

\section{The Study Areas and Methodology}

The study was conducted in two areas in Ghana, namely Accra and Cape Coast.

Ghana's capital, Accra, has an estimated population of about 3.9 million and has an annual growth rate of 3.36\%. The primacy of the Accra Metropolitan Area as Ghana's administrative, educational, industrial and commercial centre continues to be the major force for its rapid population growth, with immigration contributing to over $35 \%$ of the city's population growth. The rapid population growth makes it one of the largest and fastest-growing cities in Africa.

Cape Coast, which is the administrative capital of the Central Region, is a historic and political geographical area in the Central Region. It served as an entry point for the Europeans in the $15^{\text {th }}$ century and later served as a port, military post and a central venue for receiving and "processing" slaves from the interior during the period of the Trans-Atlantic Slave Trade. During the Gold Coast era, it served as the first national capital of Ghana and seat of government until 1877, when it lost that status to Accra, the present national capital and seat of government. Cape Coast is both the administrative and most viable commercial centre in the region with a population of about 169,894 of which 82,810 are males and 87,084 females (Ghana Statistical Service, 2012).

Cape Coast and Accra were selected as study areas because of the heterogeneous nature of their populations.

\subsection{Study Design}

This study used a descriptive research design. The researchers adopted the descriptive research design because it is used to gain more information about characteristics within a particular field of study with the view to providing a picture of situations as they naturally occur (Burns \& Grove, 2004). Since it would have been difficult to use either experiment or quasi-experiment to carry out this research, the descriptive survey design was more appropriate.

\subsection{Data Collection}

The researchers conducted the interviews in November 2013 using two semi-structured interview guides that 
contained questions on the socio-demographic background of respondents, children's knowledge about HIV and AIDS, children's reaction after parents' HIV status had been disclosed to them, parents' decision to disclose HIV status to children, reasons for disclosure and non-nondisclosure, and the effects of disclosure or nondisclosure. The interviewees, made up of 26 parents living with HIV and 21 children, a few of whom were $\mathrm{HIV}^{+}$, were recruited from Accra and Cape Coast through a combination of purposive and convenient sampling. Most of the parents were recruited at two hospitals either during their routine visit to the hospitals or during their service as "models of hope", that is volunteer caregivers, who provide care and support to fellow PLHIV in hospitals, clinics, and homes. There was only one parent recruited from a home. Six of the children were recruited at an NGO, which was taking care of children orphaned by HIV and AIDS, while the rest were invited to two centers together with their parents. Prior to the interviews, the researchers found out from the parents whether or not the children knew their statuses. This was to avoid disclosing parental HIV status to those, who did not know. They also explained the rationale for the interview and sought the interviewees' consent. All those recruited consented to participate in the interview. The respondents were interviewed in English or Akan, one of the major languages spoken in Ghana. The interviewee recruited from a home granted a telephone interview. Each interview that lasted for an average of 40 - 50 minutes was recorded in notepads after permission had been sought from the respondents.

\subsection{Data Analysis}

After the fieldwork, one of the researchers transcribed all the recorded data. He then coded the transcripts after which the other researcher identified and defined a set of themes resulting from the interviews. He then organized these themes into categories, namely disclosure, nondisclosure and effects of disclosure. He identified a core category: decision to disclose.

\subsection{Respondents' Names}

The names used for the respondents in this paper are all pseudonyms.

\section{Results}

The following section looks at the socio-demographic characteristics of the respondents, the reasons why parents either disclosed or did not disclose their status and the effects of their decision.

\section{Socio-demographic Characteristics of Parents}

The data indicate that out of a total number of 26 parents, 18 were women, while 8 were men. Seventeen of them were aged between 35 and 44 years; 4 between 30 and 34 years; 2 between 20 and 29; and only 1 person was above 50 years. Half of them were married; 7 had divorced; 5 were single; and 1 was widowed. Half of them had between one and two children; 11 between three and five children; and only 2 had more than five children. 15 of them said they had had basic level education; 1 person indicated that he had had tertiary education; 4 stated that they had had secondary education; and 6 said they had had no formal education. 10 of them indicated that they were traders. 1 person was a trained teacher; 3 were unemployed, another group of 3 were trained to support fellow PLHIV in HIV clinics; and the remaining 9 had other occupations. In terms of ethnicity, 10 out of the 26 respondents indicated that they belonged to the Ewe ethnic group; 11 belonged to the Akan ethnic group; and 5 belonged to the Ga-Adangbe ethnic group.

\section{Socio-demographic Characteristics of Children}

Out of a total number of 21 children, 15 were females, while 6 were males. A little over half of them numbering 12 were aged between 10 and 15 years; 2 between 15 and 20 years; 5 between 5 and 10 years; and only 2 were above 20 years. 9 of them were at the primary level of education; 7 were in junior high schools; 2 were in senior high schools; and 3 said they had had no formal education. 6 belonged to the Ewe ethnic group; 13 to the Akan ethnic group; and only 2 belonged to the Ga-Adangbe ethnic group.

\section{Theme 1: Decision Regarding Disclosure or Nondisclosure}

The researchers ascertained from the respondents whether they had disclosed their HIV status to their children or not. Out of the 26 of them, the majority numbering 18, made up of 2 males and 16 females had not disclosed their status to their children at all; of the remaining eight, who had disclosed their status to their children, 3 were males and 5 were females. They had children between the ages of 1 month and 26 years. Their decision to disclose was influenced by internal and external factors. With the internal factors, the disclosure happened through 
the personal initiative of respondents, while with the external factors it happened through prompting by health professionals.

A 41-year-old female respondent indicated that she did the disclosure based upon an external factor. She said:

I told my son because my healthcare providers had asked me to come along with someone and he was the one I decided to go with.

A 37-year-old mother of 5 children indicated that her disclosure was based upon an internal factor. She said:

I have disclosed my status to 3 of my children. I told them in 2008 after their father's burial. I actually told them that I am a PLHIV and that HIV killed their father.

\section{Theme 2: Reasons for Disclosure of HIV Status}

A 42-year-old father of four children indicated that he had done the disclosure, but he had to do that three years after his daughter had been stigmatized at Church by members who had gotten to know his status through a pastor to whom he had disclosed his status. He stated as follows:

I had to tell my first child about my status after she had been stigmatized by some Church members. Hmm! I actually disclosed my status to a senior pastor of my Church and he made it known to the entire congregation. Some of these members teased my daughter and avoided her and informed some community members who do not attend Church. My daughter came home and asked why people were teasing and avoiding her. I was shocked, depressed, and confused. I had no option but to disclose my status to her and calm her down.

\section{Theme 3: Reasons for Nondisclosure of HIV Status}

Some respondents were of the view that if they disclosed their status their children might think they would die.

I will not tell her about my status because if I do that she might have the feeling that I will pass on soon and that will make her very sad. She should just feel good (A 32-year-old female with a child of 18 years).

Some parents were of the view that if they told the children about their status, the children would be worried about their death because many people in Ghana, including children, know of HIV as a killer disease.

My children had an HIV education in their school and were told by the speakers that HIV kills. In view of this information I am afraid to disclose my status to them, since they might be thinking that I will die soon (A 38-year-old mother of two aged 14 and 15).

Most respondents did not disclose their status to their children because they felt that the children were too young to know the status of the HIV infected parents.

I will not disclose my status to them because I think they are too young. My first child is 12 years old and the youngest is four years old (A 36-year-old female with four children).

Many PLHIV in Ghana stigmatize themselves because they face a lot of stigmatization and discrimination in the Ghanaian society.

I do not even intend to tell them in future because the disease is a shameful one (A 36-year-old mother of four).

Some parents were worried about the fact that if they told their children, they would be worried.

My thinking is that if I tell him he will be worried. Already his father has passed on and if I disclose my status and that of his sister's to him, he might think he will be losing his mother and his only sister. I do not think it will be easy for him (A 43-year-old mother of two children).

I think when I tell them now they cannot concentrate on their studies. This is because they are emotional and I do not want to trouble them (A 39-year-old mother of four).

Some parents did not want their children to know about their status for fear that these children might let other people know because children generally do not keep secrets. 
No, I do not want her to know. I am afraid she will disclose it to other people; I will be very hurt if other persons get to know my status (A 44-year-old male with a 10-year-old child).

Some parents failed to disclose their status to their children because they feared that if they did so family members might get to know about their positive status from the children leading to stigmatization and discrimination against them.

I just do not want them [family members] to know. If I do, I risk being stigmatized (A 34-year-old mother of three).

Some parents indicated that they had the intention of disclosing their HIV status to their children in future.

In future, I will disclose my HIV status to all my children. I am a counselor so disclosing my status should not be difficult. I think when I tell them now they cannot concentrate on their studies. This is because they are emotional and I do not want to trouble them (A 39-year-old mother of four).

\section{Theme 4: The Effects of HIV Disclosure and Nondisclosure \\ Immediate Reaction after Disclosure}

The study revealed that the 11 children, who knew about the status of their parents, were affected. Most of them were initially sad about the fact that their parents were HIV positive. However, they overcame the traumatizing experience after a while. Only one parent indicated that when she disclosed her status to her 29-year-old child she did not show any surprise.

When she heard that I was HIV positive she cried all day, the relationship between us a while after the disclosure is very cordial (A 58-year-old male).

I disclosed my status to my 26-year-old child. The very day I told him he was very sad, but three days later he called me and told me that I should not worry about the disease and that it is normal; a lot of people are infected and are still living. He went on to say that in the past when people were diagnosed of HIV they refused to eat and that is what killed many of them (A 43-year-old mother).

After coming to terms with the situation of their parents, majority of the children offered care and support to their parents.

Anytime I fall sick my children become sad. If I do not get up early, they come and check on me to ascertain whether or not I am okay. They have been supportive (A 37-year-old mother of five).

Some parents indicated that they did not have any regrets for telling their children that they were HIV positive.

I have never regretted disclosing my status to him because he is so nice to me (A 43-year-old mother of a 26-year-old child).

Most of the children, who knew the status of their parents, did not only have more knowledge about HIV and AIDS than those, whose parents had not disclosed their status to them, but also supported their parents, after the initial sadness.

A 12-year-old Junior High School student, who demonstrated some knowledge about the disease, indicated that his parents were the source of the information. He stated:

I got to know about the disease through my mother's initiative to educate us [children].

\section{Discussion}

The study set out to examine parents' reasons for disclosure and nondisclosure of their HIV status to their children and the effects the decision had on them, their children and society at large. Some PLHIV and children in Cape Coast and Accra were the respondents of the study.

The results of the study show that a few parents decided to disclose their HIV status to their children based on internal and external factors. Those, who did the disclosure based upon internal factors, did that upon their own volition. These parents did not withhold the truth from the children and only told them, after they had "seen some evidence”, as pointed out by Xu, Yan, Rou, Wang, Ye, Duan, \& Wu (2007). They did it because they 
wanted some care and support from their children. Those, who did it based on external factors, did it because someone prompted them to do so. In this study, such persons were mostly prompted by healthcare providers, who wanted to disclose their status to other people, who would support them.

The majority of the respondents were, however, not willing to disclose their HIV status to their children for a number of reasons, including the fear that their children might think they would die because of children's general belief that HIV kills, their worry that their children were too young to get to know about their deadly condition, and the fear of being stigmatized and discriminated against by societal members when their children disclose their status to others because children are generally not able to keep secrets. This generally confirms previous findings in other developing countries. For instance, Moore, Kalanzi, \& Amey (2008), Zhou, Zhang, Li, \& Kaljee (2013), and Madiba (2013) observed that majority of participants of studies they conducted in Togo, China, and South Africa respectively had not disclosed their status to their children. Of all the factors mentioned, the one that actually made most respondents refuse to disclose their status was the fear of stigmatization and discrimination (Mwini-Nyaledzigbor, Wright, Ansah-Ofei, \& Atindanbila, 2013). This is because "there is the epidemic of stigma, discrimination, blame and collective denial...” in Ghana (Amoa, 2005). Because many people in Ghana seeing HIV as a shameful disease stigmatize PLHIV, many PLHIV, including some of the respondents of this study, stigmatized themselves and hid their status from other people including their children, family members, and the community at large.

Similar to previous studies conducted in well-developed countries, some respondents had the intention of disclosing their status to their children in future, when they thought these children were mature enough to understand HIV and could keep parents' status a secret (Brackis-Cott, Mellins, \& Block, 2003; Schrimshaw, \& Siegel, 2002; Vallerand, Hough, Pittiglio, \& Marvicsin, 2005 cited in Madiba, 2013). Even most of the few respondents, who had disclosed their status, did it to the children they considered mature enough. They chose not to disclose to younger children for the same reasons given by those, who had not disclosed their status. By so doing, most of the respondents were oblivious of the fact that young children could contract HIV out of ignorance.

The revelation that the majority of the children, to whom their parents' status was disclosed became sad, is similar to a study conducted by Rotheram-Borus, Draimin, Reid, \& Murphy (1997). This study revealed that the negative impact, just as the authors believed, was short-lived. The children overcame their initial sadness and provided care and support to their parents.

The study further indicated that the children, to whom the status of the parents had been disclosed, had more knowledge about HIV and AIDS compared with the children, who did not know their parents' status. This is because during the disclosure the children had the opportunity to learn about the disease, if they did not have any prior knowledge or gained more knowledge, if they already had some notions. This finding is consistent with previous studies which show that children derive a lot of benefits, when their parents' HIV status is disclosed to them (Mkwanazi, Rochat, Imrie, \& Bland, 2012).

\section{Conclusion}

Ghana has made serious efforts to reduce the impact of HIV and AIDS in the country. For example, through these efforts the prevalence rate of the disease has been reduced to 1.3 percent (Kloku, 2013). However, the country still experiences massive stigmatization and discrimination against PLHIV. This study reveals that stigma and discrimination are some of the main reasons why most parents did not disclose their status to their children. This has serious implications for HIV prevention as well as treatment, care, and support to PLHIV. Since disclosure of parents' status to their children has a lot of psychological, physical, and social benefits for both parents and children, Ghana should continue with its efforts to fight stigma and discrimination and develop interventions. By so doing more parents would have the courage not only to disclose their status to their children but also educate them on HIV and AIDS. They can, however, educate their children on HIV and AIDS correctly only if their capacity is built. This can be done in the form of skills training through which parents living with HIV and AIDS would be equipped with the requisite knowledge and skills.

\section{Acknowledgements}

The authors would like to express their profound gratitude to all the respondents of this study for making themselves available for the study. Although the words "thank you" are simple, they use them with a deep sense of gratitude to them all. They would also like to thank the "models of hope” working at the Central Regional Hos- 
pital in Cape Coast and Lekma Hospital in Accra and Mr. John Azumah of the "Heart-to-Heart" Campaign, which is spearheaded by the Ghana AIDS Commission and the National Association of Persons Living with HIV (NAP + Ghana), for their assistance in identifying and recruiting the respondents.

\section{Competing Interests}

The authors declare that the writing of this article has in no way been influenced by personal and/or financial relationships.

\section{Authors' Contributions}

RA carried out the conception of the paper and contributed to its design as well as the collection, analysis, and interpretation of the data. After that, he prepared a draft manuscript, revised it, and participated in the approval of its final version.

JA contributed to the collection, analysis and interpretation of data and approved of the final version of the manuscript.

\section{References}

Amoa, S. A. (2005). Facing the Challenge: A Serious Dialogue about HIV/AIDS. Accra, Ghana: Step Publishers.

Bachanas, P. J., Kullgren, K. A., Schwartz, K. S., Lanier, B., McDaniel, J. S., Smith, J., \& Nesheim, S. (2001). Predictors of Psychological Adjustment in School-Age Children Infected with HIV. Journal of Pediatric Psychology, 26, 343-352.

Brackis-Cott, E., Mellins, C., \& Block, M. (2003). Current Life Concerns of Early Adolescents and Their Mothers: Influence of Maternal HIV. The Journal of Early Adolescence, 23, 51-77. http://dx.doi.org/10.1177/0272431602239130

Burns, N., \& Grove, S. (2004). The Practice of Nursing Research: Conduct, Critique and Utilization. Philadelphia, PA: Saunders.

Ghana Statistical Service (2012). Population and Housing Census. Summary Report of Final Results. Ghana Statistical Service. Accra: Sakoa Press Ltd.

Kloku, M. (2013). The Ghana AIDS Control Programme Released Report for 2012. www.myghanaonline.com/?id=1.1416429

Madiba, S. (2013). The Impact of Fear, Secrecy, and Stigma on Parental Disclosure of HIV Status to Children: A Qualitative Exploration with HIV-Positive Parents Attending an AIDS Clinic in South Africa. Global Journal of Health Science, 5, 49-61.

Mkwanazi, N. B., Rochat, T. J., Imrie, J., \& Bland, R. M. (2012). Disclosure of Maternal HIV Status to Children: Considerations for Research and Practice in Sub-Saharan Africa. Future Virology, 7, 1159-1182. http://dx.doi.org/10.2217/fvl.12.109

Moore, A., Kalanzi, D. N., \& Amey, F. (2008). To Disclose or Not to Disclose? Lower Class Parents Living with HIV/AIDS in Lomé, Togo. International Journal of Sociology and Social Policy, 28, 351-364. http://dx.doi.org/10.1108/01443330810900194

Mwini-Nyaledzigbor, P. P., Wright, S. D. C., Ansah-Ofei, A. M., \& Atindanbila, S. (2013). Betwixt and between Telling and Not Telling: HIV Infection Disclosure Dilemmas among Ghanaian Women. Wudpecker Journal of Medical Sciences, 2, 034-040.

Qiao, S., Li, X., \& Stanton, B. (2013). Disclosure of Parental HIV Infection to Children: A Systematic Review of Global Literature. AIDS and Behavior, 17, 369-389. http://dx.doi.org/10.1007/s10461-011-0069-x

Rotheram-Borus, M. J., Draimin, B. H., Reid, H. M., \& Murphy, D. A. (1997). The Impact of Illness Disclosure and Custody Plans on Adolescents Whose Parents Live with AIDS. AIDS, 11, 1159-1164.

http://dx.doi.org/10.1097/00002030-199709000-00012

Schrimshaw, E. W., \& Siegel, K. (2002). HIV-Infected Mothers’ Disclosure to Their Uninfected Children: Rates, Reasons, and Reactions. Journal of Social and Personal Relationships, 19, 19-43. http://dx.doi.org/10.1177/0265407502191002

Vallerand, A. H., Hough, E., Pittiglio, L., \& Marvicsin, D. (2005). The Process of Disclosing HIV Serostatus between HIVPositive Mothers and Their HIV-Negative Children. AIDS Patient Care STDS, 19, 100-109.

http://dx.doi.org/10.1089/apc.2005.19.100

Xu, T., Yan, Z., Rou, K., Wang, C., Ye, R., Duan, S., \& Wu, Z. (2007). Disclosure of Parental HIV/AIDS to Children in Rural China. Vulnerable Children and Youth Studies, 2, 100-105. http://dx.doi.org/10.1080/17450120701335791

Zhou, Y., Zhang, L., Li, X., \& Kaljee, L. (2013). Do Chinese Parents with HIV Tell Their Children the Truth? A Qualitative Preliminary Study of Parental HIV Disclosure in China. Child: Care, Health and Development, 39, 816-824. 
Scientific Research Publishing (SCIRP) is one of the largest Open Access journal publishers. It is currently publishing more than 200 open access, online, peer-reviewed journals covering a wide range of academic disciplines. SCIRP serves the worldwide academic communities and contributes to the progress and application of science with its publication.

Other selected journals from SCIRP are listed as below. Submit your manuscript to us via either submit@scirp.org or Online Submission Portal.
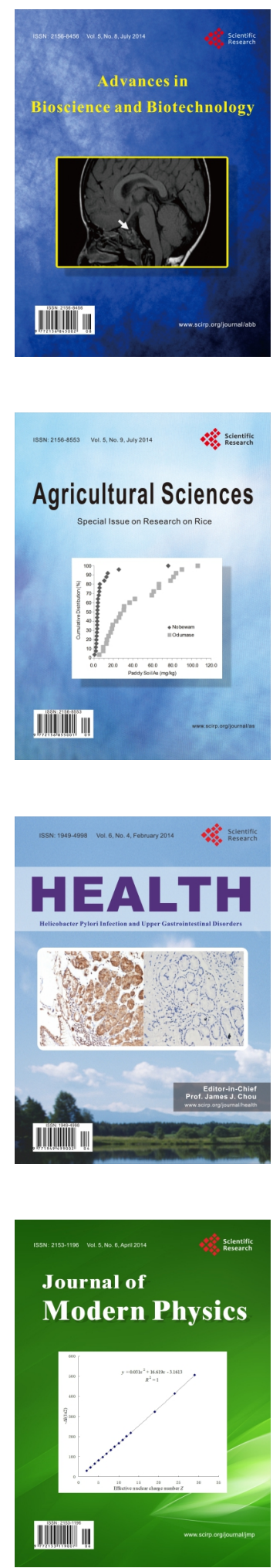
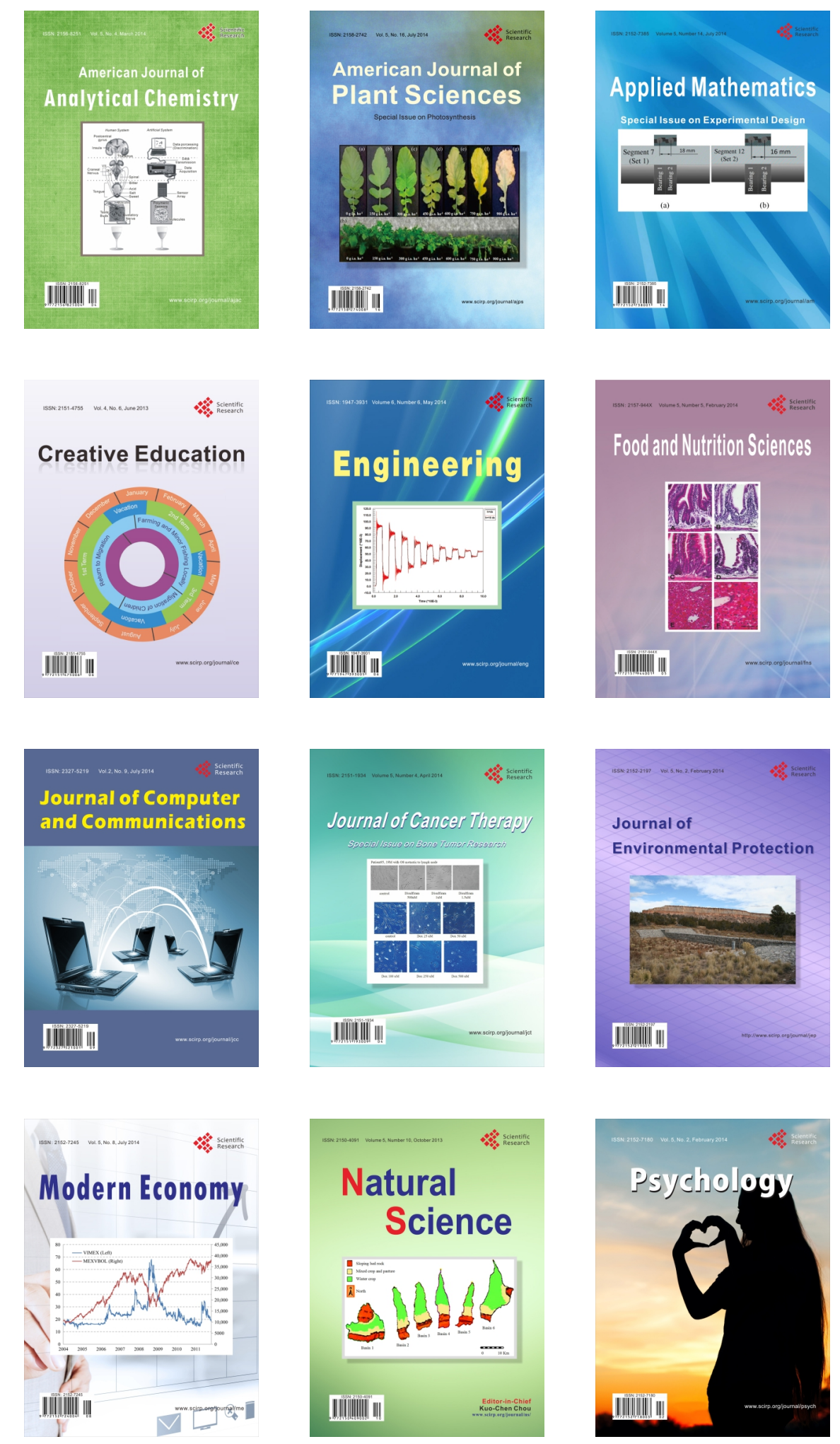